\title{
The Incidence of Thyroid Carcinoma in Multinodular Goiter: A Retro- spective Study
}

\author{
D. Shrestha ${ }^{1,2}$, S. Shrestha ${ }^{2}$ \\ ${ }^{1}$ Department of ENT and Head and Neck Surgery, NAMS, Bir Hospital, Kathmandu; Alka Hospital, Lalitpur \\ ${ }^{2}$ Alka Hospital, Lalitpur
}

\section{Correspondence}

\section{Dr. Deependra Shrestha}

Associate Professor, Department of ENT and Head and Neck Surgery, NAMS, Bir Hospital, Kathmandu;

Consultant ENT surgeon, Alka Hospital, Lalitpur

E-mail: shrestha_deependra@gmail.com

DOI: http://dx.doi.org/10.3126/

jcmsn.v10i4.12974

\begin{abstract}
Background and Objective: To determine the incidence and the types of various thyroid malignancies in multi-nodular goiter. Material and methods: This is a retrospective study, conducted in Department of ENT and Head and Neck Surgery, National Academy of Medical Sciences Bir Hospital Kathmandu and Alka Hospital Pvt. Ltd Lalitpur. The study period was 3 years from 11 January 2011 to 10 January 2014. The study population consisted of 100 patients who were diagnosed as a multinodular thyroid nodule. Result: The highest frequency was 50 $(50 \%)$ in 31-40 years. Among the total cases, $28(28 \%)$ were males and $72(72 \%)$ females. Histopathological analysis showed that benign multinodular goiter was present in $87(87 \%)$ cases, and malignant thyroid lesion in $13(13 \%)$ cases. Among malignancies, papillary carcinoma was found as the commonest malignancy $11(84.61 \%)$ cases followed by follicular carcinoma $1(7.69 \%)$ case and anaplastic carcinoma 1 $(7.69 \%)$ case. Conclusion: The risk of malignancy in multinodular goiter should not be underestimated as significant number of patients with thyroid malignancies present with multinodular goiter.
\end{abstract}

Keywords: Multinodular Goiter, Thyroid malignancy. Papillary carcinoma

Citation: Shrestha D, Shrestha S. The incidence of thyroid carcinoma in Multinodular goiter: A retrospective study. JCMS Nepal 2014;10(4):18-21.

\section{INTRODUCTION}

Thyroid nodule is probably one of the commonest endocrine problem in the world. The frequency of thyroid nodule increases throughout life. ${ }^{1}$ In a study lifetime risk of developing a thyroid nodule was estimated 5 to $10 \% .^{2}$ A nodule may be solitary thyroid nodule or dominant nodule of multinodular goiter which is due to focal anatomical lesions, such as thyroid cyst, adenoma or malignancy. ${ }^{3}$ Multinodular goiter (MNG) is a clinicopathological entity characterized by an increased volume of the thyroid gland with formation of nodules. Multinodular goiter is endemic in regions with low iodine in the soil, such as countries in the mountainous areas in south-East Asia, Latin America and Central Africa. The World Health Organization reported a worldwide iodine deficiency rate 9.8$56.9 \%$ and total goiter prevalence of $4.7-37.3 \%$ by year $2003 .^{4}$

In the US, clinically apparent nodule are present in $4-7 \%$ of adult population and more common in women than men. ${ }^{5}$ The incidence of malignancy vary from country to country and with the changing methods of evaluation. A long standing and hitherto unresolved issue is whether Multinodular goiter is significantly associated with malignancy. ${ }^{6}$ Multinodular goiter had been traditionally thought to be at a low risk for malignancy as compared to solitary thyroid nodule. ${ }^{7,8,9}$ However, various studies have reported a 7 to $17 \%$ incidence of malignancy in Multinodular goiter. $8,10,11$. 
There has been controversy in the literature about the risk of thyroid cancer in patients with multinodular goiter. Initially, studies suggested that the patients with multinodular goiter and toxic nodular goiter carried a lower risk of thyroid cancer than patients with only a single thyroid nodule. However, recent studies suggested a higher risk of cancer in these patients $(10-20 \%){ }^{12}$

Epidemiologically ascertained risk factors are ionizing radiation, the presence of thyroid adenoma and multinodular goiter. Multinodularity of goiter should no longer be considered an indicator of probable benign diseases. The objective of this study was to determine the incidence and the types of various thyroid malignancies in multi-nodular goiter by doing the histopathological examination of thyroidectomy specimens.

\section{MATERIALS AND METHODS}

This is a retrospective study, conducted in Department of ENT and Head and Neck Surgery, National Academy of Medical Sciences Bir Hospital Kathmandu and Alka hospital Pvt. Ltd Lalitpur. The study period was 3 years from 11 January 2011 to 10 January 2014 . The study population consisted of 100 patients who were diagnosed as a Multi nodular thyroid nodule.

Patients with multinodular thyroid disease of all ages and both sexes, euthyroid clinically and biochemically were included in the study. Those cases of multinodular goiter confirmed by USG of the thyroid gland were scheduled for thyroidectomy. Patients with solitary thyroid nodule and not in euthyroid state were excluded.

All the patients underwent different thyroid operations ranging from hemithyroidectomy to total thyroidectomy and the resected specimens were sent for Histopathological examination. Age, gender, address, USG findings and Histopathological findings were recorded in a proforma.

\section{RESULT}

Table 1: Age and sex distribution of the patients

\begin{tabular}{|c|c|c|c|}
\hline $\begin{array}{c}\text { Age groups } \\
\text { (years) }\end{array}$ & Male & Female & Total (\%) \\
\hline $11-20$ & 0 & 05 & $04(4.0)$ \\
\hline $21-30$ & 02 & 16 & $18(18.0)$ \\
\hline $31-40$ & 12 & 38 & $50(50.0)$ \\
\hline $41-50$ & 06 & 08 & $14(14.0)$ \\
\hline $51-60$ & 08 & 02 & $10(10.0)$ \\
\hline $61-70$ & 0 & 04 & $0494.0)$ \\
\hline Total & 28 & 72 & $100(100.0)$ \\
\hline
\end{tabular}

Table 2: Histopathological findings

\begin{tabular}{|l|c|}
\hline HPE Findings & No. of Cases \\
\hline Benign multinodular goiter & $87(87 \%)$ \\
\hline Malignant thyroid lesion & $13(13 \%)$ \\
\hline Total & 100 \\
\hline
\end{tabular}

Table 3: Distribution of thyroid malignancies

\begin{tabular}{|l|c|}
\hline HPE Findings & No. of Cases \\
\hline Papillary thyroid carcinoma & $11(84.61 \%)$ \\
\hline Follicular carcinoma & $01(7.69 \%)$ \\
\hline Anaplastic carcinoma & $01(7.69)$ \\
\hline Total & $13(100 \%)$ \\
\hline
\end{tabular}

\section{DISCUSSION}

Multinodular goiter (MNG) is defined as the palpation of multiple discrete nodules in the enlarged thyroid gland. The etiology and pathogenesis of the MNG is not very clear. A mild dietary deficiency of iodine, slight impairment of hormone synthesis, increased iodide clearance from the kidney and the presence of thyroid stimulating immunoglobulins have been suggested as the various causes. ${ }^{12}$ Traditionally, patients with multinodular goiter have been considered at lower risk of malignancy than those with solitary thyroid nodule. However, the literature review has shown that the incidence of malignant tumors in patients with solitary nodule doesnot differ much from those with multinodular goiter. $^{13}$ 
Multinodular goiter is the commonest endocrine problem worldwide. The incidence of malignancy in thyroid nodule vary from country to country. Appropriate surgical interventions can reduce the higher rates of morbidity and mortality.

In this study 100 patients with multinodular goiter were studied. The highest frequency was $50(50 \%)$ cases in 31-40 years which is correlated with the study of Rahman, Nath, Sattar. ${ }^{14,15}$ The youngest patient in this study was 19 years with papillary carcinoma and oldest 70 years old female with anaplastic carcinoma, showing the extreme of ages has more chance to be malignant.

Male female ratio was 1:2.6 in our study. In a study done by Pedamallu ${ }^{9}$ multinodular goiter was found to be higher in females (88\%) compared to that of males $(12 \%)$. Female preponderance is seen in all other studies. This ratio was shown 1:5 by Rahman, ${ }^{14} 1: 4$ by Welkar, ${ }^{17} 1: 2.5$ to 4.1 by Zuberi. ${ }^{18}$

Histopathological analysis showed that benign multinodular goiter was present in $87(87 \%)$ cases, and malignant thyroid lesion in $13(13 \%)$ cases. This is consistent with the figures from various international studies. Benzarti found a $9.5 \%$ incidence of malignancy in multinodular goiter. Prades ${ }^{19}$ from France reported the incidence of malignancy $12.25 \%$ in multinodular goiter. Mofti ${ }^{20}$ however observed higher incidence of thyroid malignancy $29 \%$ in a study of 158 patients.

Among malignancies, papillary carcinoma was found as the commonest malignancy $(84.61 \%)$ followed by follicular carcinoma (7.69\%) and anaplastic carcinoma $(7.69 \%)$. This finding is consistent with the observation made in most of the literatures and international studies. ${ }^{21,22 .}$

\section{CONCLUSION}

Multinodular goiter is one of the common problem of thyroid disease in all ages. Female was more commonly affected than male. The highest number were found in $30-40$ years age group.
The frequency of malignancy in this study was $13 \%$. Among the malignancies papillary carcinoma was the most common (84.61\%) followed by follicular carcinoma and anaplastic carcinoma. Clinical importance of Thyroid nodule is exclusion of malignancy. The risk of malignancy in multinodular goiter should not be underestimated as significant numbers of patients with thyroid malignancies present with multinodular goiter.

\section{REFERENCES}

1. Adwok JA. Evaluation and surgical treatment of solitary thyroid nodules. East Afr Med J 1995;72:191-3.

2. Langer P. Discussion about the limit between normal thyroid and goiter: Mini review. Endocrine regulations 1999.

3. Vander JB, Gaston EA, Dawber TR. Significance of solitary nontoxic thyroid nodules. N Engl J Med 1954;251:970-3. DOI:10.1056/NEJM195412092512403. PMid:13214371.

4. WHO, Iodine status Worldwide, WHO global database on Iodine Deficiency, World health Organization department of Nutrition for health and Development, Geneva, Switzerland,2004.

5. Rojeski MT, Gharib H. Nodular thyroid disease : Evaluation and management. N Engl J Med 1985;313:428-36. DOI:10.1056/NEJM198508153130707. PMid:3894966.

6. Abu-Eshy SA, Khan AR, Khan GM, et al. Thyroid malignancy in multinodular goiter and in a solitary nodule. JR Coll Surg Edinb 1995;40:310-12. PMid:8523308.

7. Memon W, Khanzada TW, Samad A, et al. Incidence of thyroid carcinoma in multi-nodular goiters. Rawal Med J 2010;35.

8. Gandolfi PP, Frisina A, Raffa M, et al. The incidence of thyroid carcinoma in multi-nodular goiter : A retrospective analysis. Acta Bio medica Ateneo Parmense 2004;75;114-17.

9. R Pedamallu, S Pedamallu, K Rama Rao. Incidence of occult carcinoma in multinodular goiter using histopathological findings. The internet journal of Surgery.2008;17(1). Available at: https://ispub.com/ IJS/17/1/6545. Accessed: $7^{\text {th }}$ Dec 2014 .

10. Cole WH. Incidence of carcinoma of thyroid in nodular goiter. Semin Surg Oncol 1991;7(2):61-63.DOI: 10.1002/ ssu.2980070203. PMid:2034940.

11. Sachmechi I, Miller E, Varatharajah R, et al. Thyroid carcinoma in the single cold nodules and in the cold nodules of multi-nodular goiter. Endocr Pract 2000;6(1):11012 .

12. Memon D, De gonzalez A, Luqmani Y, et al. Family histroy of benign thyroid diseases and cancer and risk of thyroid cancer. Eur J cancer 2004;40(5):754-60. DOI: 10.1016/j.ejca.2003.12.011. PMid:15010077. 
13. McCall A, Jarosz H, Lawerence AM, et al. The incidence of Thyroid carcinoma in solitary thyroid nodule and multinodular goiter. Surgery 1986;100:1128-32. PMid:3787469.

14. Rahaman MJ, Mustafa MG .Comparative study of cancer developing in solitary thyroid nodule and multi-nodular goitre. Bangladesh J of Otorhinolaryngology 2006;6(11):6 -12 .

15. Sattar MA, Alam MR, Haider A. Clinico pathological study of solitary cold thyroid nodule. Bangladesh $\mathrm{J}$ of Otorhinolaryngology 2003;9(1):24-27.

16. Najum ul Haq R, Ali Khan B, Ahmed Chaudhary J. Prevalence of malignancy in goiter- a review of 718 thyroidecomies. J Ayub Med Coll Abbottabad 2009;21(4).

17. Welker MJ \& Lov. Thyroid nodules. American family Physician, Feb.1:1-11.

18. Zuberi LM, Yawar A, Islam \& Jabbar A. Clinical presentation of thyroid cancer patients in Pakistan-AKUH Experience. Journal of Pakistan Association, 2009;Available from http://JPMA.org.pk/view article, accessed $7^{\text {th }}$ Dec 2014. 19

19. Prades JM, Dumollard JM, Timoshenko A, et al. Multinodular goiter: Surgical management and histopatholical findings. Eur Arch Otolaryngol 2002;259;217-21.

20. Mofti AB, Al Monen AA, Suleiman Si, et al. Experience with thyroid surgery in security force hospital. Riyadh Saudi Med J 1991;12:504-6.

21. Hussain N, Anwar M, Nadia n, Ali Z. Pattern of surgically treated thyroid disease in Karachi. Biomedia 2005;21:1820 .

22. Khan AZ, Naqi Sa, Kamal AL. Thyroidectomy in carcinoma thyroid- A three years' experience. Ann King Edward Med Coll 2004;10:368-9. 